\title{
A Study on the Relationship between Tourism Industry and Regional Economic Growth-A Case Study of Jiangsu Gaochun District ${ }^{*}$
}

\author{
Baoqian Wang, Meilin Xia \\ Business School, Hohai University, Nanjing, China \\ Email: bq64@163.com; xiameilin754@126.com
}

Received May 19, 2013; revised June 19, 2013; accepted July 10, 2013

Copyright (C) 2013 Baoqian Wang, Meilin Xia. This is an open access article distributed under the Creative Commons Attribution License, which permits unrestricted use, distribution, and reproduction in any medium, provided the original work is properly cited.

\begin{abstract}
According to the tourism income and GDP data of Gaochun district from year 2001 to 2011, by using ADF unit root test, it can draw to a conclusion that the series of the economic growth (GDP) and the tourism revenue (TOUR) of Gaochun district shows first-order difference stationary. This paper confirms that there is a long-term integration relationship between the economic growth of Gaochun and tourism revenue and study the dynamic coherence between economic growth and tourism revenue by using error correction model and dynamic conditional correlation. As is shown by the Granger causality test, "GDP of Gaochun is the Granger reason for tourism revenue" while "tourism revenue is not the Granger reason for GDP".
\end{abstract}

Keywords: Regional Economy; Tourism Industry; Economic Growth

\section{A Review on the Study of the Relationship of Tourism and Economic Growth}

With the rapid development of economy and the improvement of the level of material life, as the emerging industry of the tertiary industry, tourism plays a more important role in economic growth. Gaochun district in Jiangsu province was awarded as China's first "international slow city" by the world slow city organization in November, 2011, and according to the 11th basic competitiveness of country economy, Gaochun has ranked No. 99 among the top 100 countries. Gaochun district takes tourism as a new economic growth point in the Twelve-Five planning and develops tourism energetically. Thus, it has very important theoretical and practical value to study the relationship between tourism and economic growth and the regional industry correlation effect.

Foreign researches on relationship between tourism and economic growth can be traced back to Bodio's [1] analysis on tourist consumption in Italy, later, Balaguer and Cantavella-Jorda [2] analyzed the first quarter data of year 1975 to 1997 by using the econometric model test for Spain and got a result that there is a long-term stable relationship between tourism development and economic

*This study is funded by the project City Water Source Protection and Livelihood Improvement. growth and tourism has a leading role to economic growth. By researching on the relationship between the tourism and economic growth of Fiji by using General Equilibrium Model, Narayan [3] found that tourism consumption increase by $10 \%$ while GDP will increase by $0.5 \%$. Dritsakis [4] studied on the tourism data from 1960 to 2000 of Greece and got the result that there is mutual promotion between tourism and economic growth. Kim [5] studied the data from 1971 to 2003 of Taiwan and got a result that there is a long-term equilibrium and mutual causality relationship. Brida [6] studied on Mexico and proved that tourism has a pulling effect on economic growth by using co-integration test and causality test.

Domestic researches on the relationship between tourism and economic growth are also made from the aspect about the interaction of the two. Ling Gang, Long Xiongbiao [7] proved that tourism is the pillar industry to pull the economic growth of Guilin by researching on the relationship between tourism and economic growth of Guilin. Li Zhiqing [8] revealed the leading role of tourism to Shanghai by analyzing the contribution made by tourism to economic growth and the multiplier effect of tourism in Shanghai. Wu Guoxin [9] concluded that tourism has a positive effect on the economy in China by making a quantitative and empirical analysis on the tour- 
ism industry in China.

Above all, the results of the research on the relationship between tourism and economic growth are not the same. Because of the differences in regional samples, research methods, and the research objects are mainly national, provincial and city level, the country level is almost blank. Therefore, this paper researches on the relationship between tourism development and economic growth of Gaochun district based on the VAR model, co-integration theory and the data of year 2001 to 2011 , and aims to provide some empirical materials for researches on tourism and economic growth of country's economy.

\section{The Current Situation of Tourism and the Economic Structure of Gaochun District}

\subsection{Current Situation of the Tourism Development of Gaochun}

The tourism of Gaochun stated late in 1999, after 3 years' start construction from 1999 to 2001, it is the stage of the formation of tourism from 2002 to 2004. Since year 2005, the tourism of Gaochun has developed quickly and entered into a new stage after the Yaxitown of Gaochun was rated as China's first "Slow City" in November, 2011. It can be seen from Figure 1 about the tourism revenue trend along with the change of time and the probably growth trend of the share of tourism to GDP. As seen from the tourism income, there is an obvious increasing trend of tourism revenue and tourism revenue increased from 78 million Yuan in 2001 to 241 million YUAN in 2011, the actual growth is nearly 30 times. As seen from the point of the share of tourism income to GDP, there is also a rising trend from 2001 to 2011. In 2001 , tourism revenues accounted for 1.73 of the GDP of Gaochun district and by 2011 it has accounted for $8.19 \%$.

\subsection{Economic Structure and Correlation Coefficient of Gaochun District}

Regional economic development is the result of the cooperation of different industries, there is an input and

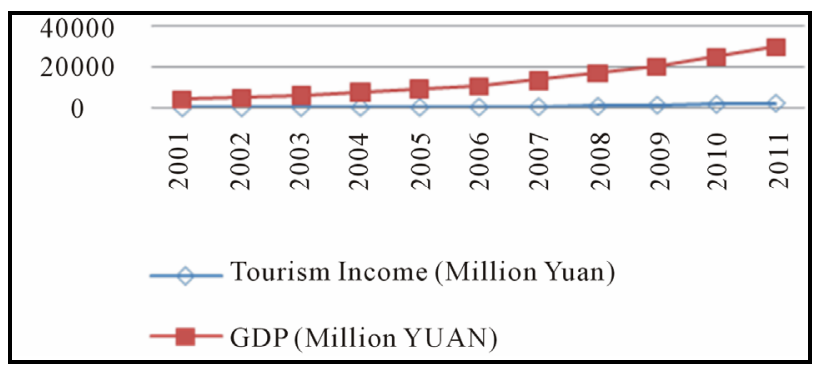

Figure 1. Tourism income and GDP of Gaochun district (2) economic structure and correlation coefficient of Gaochun district. output relationship among them. In order to better grasp the status of tourism in the economy of Gaochun District, this paper firstly studies the input structure and associated effect between tourism and other industries.

Input and output structure reflects that $\mathrm{X}$ industry provides intermediate input for other economic production department and the production technology connection between $\mathrm{X}$ industry and other industries, and the connection is measured by Direct Consumption Coefficient. The computational formula of direct consumption coefficient is:

$$
a_{i j}=x_{i j} / X_{j} \quad i, j=(1,2, \ldots, n)
$$

$x_{i j}$ represents for the product quantity that department $j$ directly consumes from department $i, x_{j}$ represents for the total input value of department $j$, all the direct consumption coefficient form the matrix

$$
\mathrm{A}=\left(a_{i j}\right)_{n^{*} n}
$$

the direct consumption coefficient $a_{i j}$ is used to reflect the dependence relationship between two departments, the greater $a_{i j}$ is, the interdependence between the two departments higher.

According to the calculation, the direct consumption coefficient of the tourism to other economic production departments is shown in Table 1.

The relevancy of tourism and other industries can be

\begin{tabular}{|c|c|c|c|}
\hline $\begin{array}{c}\text { Industry } \\
\text { Department }\end{array}$ & $\begin{array}{c}\text { Direct } \\
\text { Consumption } \\
\text { Coefficient }\end{array}$ & $\begin{array}{c}\text { Industry } \\
\text { Department }\end{array}$ & $\begin{array}{c}\text { Direct } \\
\text { Consumption } \\
\text { Coefficient }\end{array}$ \\
\hline Agriculture & 0.000000 & $\begin{array}{l}\text { Leasing and Business } \\
\text { Service }\end{array}$ & 0.140612 \\
\hline Manufacture & 0.100784 & Scientific Research & 0.000000 \\
\hline $\begin{array}{l}\text { Construction } \\
\text { Industry }\end{array}$ & 0.000000 & $\begin{array}{c}\text { Pipe Water } \\
\text { Environment and } \\
\text { Public Facilities }\end{array}$ & 0.000008 \\
\hline $\begin{array}{l}\text { Transportation, } \\
\text { Warehousing and } \\
\text { Postal Service }\end{array}$ & 0.152050 & $\begin{array}{l}\text { Resident Services } \\
\text { and Other Services }\end{array}$ & 0.001766 \\
\hline $\begin{array}{c}\text { Information } \\
\text { Transmission, } \\
\text { Computer Services } \\
\text { and Software }\end{array}$ & 0.193447 & Educational Business & 0.000000 \\
\hline $\begin{array}{l}\text { Wholesale and } \\
\text { Retail Sale Trade }\end{array}$ & 0.047086 & $\begin{array}{l}\text { Social Security and } \\
\text { Social Health Industry }\end{array}$ & 0.000000 \\
\hline $\begin{array}{c}\text { Hotels and } \\
\text { Catering Service } \\
\text { Industry }\end{array}$ & 0.202079 & $\begin{array}{c}\text { Culture, Sports } \\
\text { and Entertainment }\end{array}$ & 0.000392 \\
\hline Finance & 0.169315 & $\begin{array}{c}\text { Public Management } \\
\text { and Social } \\
\text { Organization }\end{array}$ & 0.000000 \\
\hline Realty Business & 0.024328 & Tourism & 0.493501 \\
\hline $\begin{array}{c}\text { Technology } \\
\text { Service }\end{array}$ & 0.000000 & & \\
\hline
\end{tabular}

Table 1. Direct consumption coefficient of tourism.

Data sources: 2007 Input-Output Tables of Jiangsu and 2011 Statistical Yearbook of Gaochun District. 
seen from the direct consumption coefficient in Table 1, and the industries of Gaochun district can be divided into three classes: the first class is industries that have more connection with tourism such as Transportation, Warehousing and Postal Service, Manufacture, Finance, Hotels and Catering Service Industry, Leasing and Business Service, Tourism, Transmission, Computer Services and Software. The second class is industries that have less connection with tourism such as Agriculture, Culture, Sports and Entertainment, Wholesale and Retail Sale Trade, Realty Business and Resident Services and Other Services. The third class is industries that has almost no connection with tourism such as Educational Business, Scientific Research, Public Management and Social Organization and Social Security and Social Health Industry.

\section{The Empirical Analysis on Tourism and Regional Economic Growth}

\subsection{Selection of Variables and Models}

Usually, indexes used to describe the development of tourism have a number of travels (domestic and international tourist arrivals), tourism revenue (domestic tourism income or international tourism income, etc.) and total tourism investment and so on. Considering the convenience and efficiency of the data acquisition, this paper selects tourism income of Gaochun as indicator of tourism development and GDP as a measure of economic growth.

This paper analyzes the correlation between tourism income and economic growth by using regression analysis, and makes the Granger causality test on GDP and tourism revenue by using the vector auto-regression method at the same time, and establishes the vector autoregression model between tourism and GDP, to analyze the interaction between tourism development and country economic growth.

Vector auto-regressive (VAR) model takes the form of simultaneous equations and it is not on the basis of economic theory. In each equation of the model, the endogenous variable of the model makes regression to the whole lagged values of the endogenous variables, and estimate the dynamic relation of all the endogenous variables.

Suppose there is relationship between $y_{1, t}$ and $y_{2, t}$, if there are two auto-regressive models

$$
y_{1, t}=f\left(y_{1, t-1}, y_{1, t-2}, \cdots\right) y_{2, t}=f\left(y_{2, t-1}, y_{2, t-2}, \cdots\right)
$$

which are respectively set up, it is unable to capture the relationship between the two variables. If we adopt the method of simultaneous equations, we can establish the relationship between the two variables. VAR model is related to two parameters, one is the number of variables contained in $N$, and the other is the largest lag order $K$.
Take the VAR model which has two variables $y_{1, t}$ and $y_{2, t}$ as example:

$$
\begin{gathered}
y_{1, t}=c_{1}+\pi_{11.1} y_{1, t-1}+\pi_{12.1} y_{2, t-1}+u_{1 t} \\
y_{2, t}=c_{2}+\pi_{21.1} y_{1, t-1}+\pi_{22.1} y_{2, t-1}+u_{2 t}
\end{gathered}
$$

$u_{1 t}, u_{2} \sim \operatorname{IID}\left(0, \sigma^{2}\right), \operatorname{Cov}\left(u_{1 t}, u_{2 t}\right)=0$. Written into matrix form is:

$$
\left[\begin{array}{l}
y_{1 t} \\
y_{2 t}
\end{array}\right]=\left[\begin{array}{l}
c_{1} \\
c_{2}
\end{array}\right]+\left[\begin{array}{ll}
\pi_{11.1} & \pi_{12.1} \\
\pi_{21.1} & \pi_{22.1}
\end{array}\right]\left[\begin{array}{l}
y_{1, t-1} \\
y_{2, t-1}
\end{array}\right]+\left[\begin{array}{l}
u_{1 t} \\
u_{2 t}
\end{array}\right]
$$

That is:

$$
Y_{t}=c+\Pi_{1} Y_{t-1}+u_{t},
$$

then, VAR mode which has $N$ variables and lags $K$ is :

$$
Y_{t}=c+\Pi_{1} Y_{t-1}+\Pi_{2} Y_{t-2}+\cdots+\Pi_{k} Y_{t-k}+u_{t}
$$

$u_{t} \sim \operatorname{IID}(0, \Omega) y_{t}$ is $N$-dimensional endogenous variable, $\Pi_{i}(I=1,2,3, \cdots, k)$ is the parameter matrix which is to be estimated, $u_{t}$ is stochastic disturbance, which is also called pulse vector.

\subsection{Selection and Preprocessing of Sample Data}

This paper is based on annual data, according to data availability, select the travel data of Gaochun district from year 2001 to 2011, and select annual GDP and tourism revenue as research variables. The data is mainly from Gaochun Statistical Yearbook and Gaochun Country Annals. The sample data is shown in Table 2.

In the process of empirical research, there exists lagging of most economic data, we logarithm the data to eliminate the heteroscedasticity of economic time series data, which is LGDP and LTOUR. The sequence chart of LGDP and LTOUR after logarithm processing is as shown in Figure 2.

It can be seen from Figure 2 that the change of LGDP and LTOUR from year 2001 to 2011 is non-stationary, but both of them have a common upward development trend.

\subsection{Stationary Test}

In order to probe whether tourism of Gaochun has a sig-

Table 2. Statistical table of Gaochun GDP and tourism income from 2001 to 2011 unit: million YUAN.

\begin{tabular}{cccccc}
\hline Year & GDP & TOUR & Year & GDP & TOUR \\
\hline 2001 & 44.83 & 0.78 & 2007 & 135.24 & 5.78 \\
2002 & 52.19 & 1.18 & 2008 & 168.21 & 7.55 \\
2003 & 64.07 & 1.74 & 2009 & 200.51 & 13.80 \\
2004 & 77.35 & 2.35 & 2010 & 247.26 & 17.80 \\
2005 & 93.01 & 3.27 & 2011 & 294.25 & 23.16 \\
2006 & 108.38 & 4.26 & & & \\
\hline
\end{tabular}




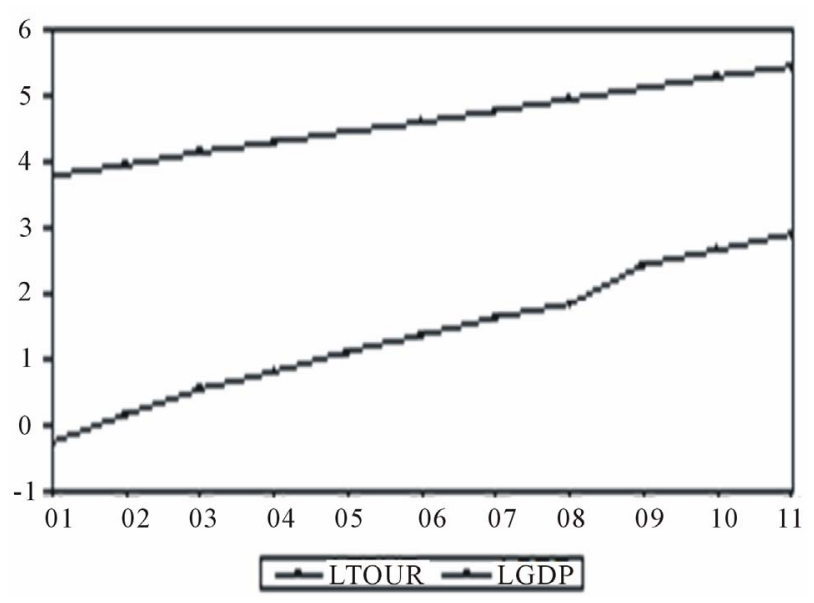

Figure 2. Sequence charts of LGDP and LTOUR.

nificant impact on economic growth, it is necessary to prove whether there is corresponding causality between them. Before carrying on the Granger causality test, we must first determine the time sequence of random variables is smooth and otherwise "Spurious Regression" phenomenon may occur and lead to wrong conclusions. Therefore, we first use ADF test to verify the stability of time series data.

The stationary test results are shown in Table 3 .

It can be seen from Table 3 that when the critical value is $1 \%$ to $5 \%$, ADF results can not pass the inspection, and that means the data is non-stationary. After first order difference between the two, when the critical value is $5 \%$ to $10 \%$, the ADF results of DLGDP and DLTOUR can pass the inspection, so we can reject the null hypothesis, and the series is a single integer column. That is to say, DLGDP and DLTOUR are all stationary time series. Thus, LGDP and LTOUR can be established models by using traditional regression functions, but we can use co-integration theory and VECM to study the long-term equilibrium relationship between them.

\subsection{Co-Integration Test of LGDP and LTOUR}

The main ideas of the co-integration test are: if two or more than two non-stationary time series are the same order integration, then the linear combination between variables may be smooth, namely there may be long-term stable equilibrium relationship between variables (cointegration relationship).There are usually two ways to inspect the co-integration relation between variables: EC method and Johansen Maximum Likelihood Estimation. Due to the sample size for EC method must be large enough and the sample size of this paper is small, we use the Johansen Maximum Likelihood Estimation method to make co-integration test in this paper.

Unit root test gives a result that both LGDP and LTOUR are first order list, so there is some stationary liner combination between the two variables and continue to make co-integration analysis. Before inspection, establish a reasonable lag period for the VAR system. The optimal lag is 2 according to the residual error analysis of unconstrained VAR model and AIC criterion, and the optimal lag order number is 1 . The results of cointegration test are shown in Tables 4 and 5.

It can be seen from Tables $\mathbf{4}$ and $\mathbf{5}$ that Trace statistics is $13.23494>12.32090,0.160501<4.129906$ and Maxeigenvalue statistics is $13.07443>11.22480,0.160501<$ 4.129906 under the significance level 5\%. Therefore, there is only one co-integration relationship between LGDP and LTOUR under the significance level 5\%. According to Granger theory, if there is co-integration between non-stationary variables, the co-integration function is:

$$
\text { vecm }=\text { LGDP }-0.510958 \text { LTOUR }
$$

the co-integration function (8) reflects the long-term stationary relationship between LGDP and LTOUR. On one side, the function reveals the long-term stationary relationship between GDP and tourism revenue of Gaochun, and on the other side, it reveals the long-term elasticity between economic growth and tourism income, namely the domestic tourism income increases by 1 percent, the economy of Gaochun increases by 0.51 percent.

\subsection{Granger Causality Tests}

There is a long-term stationary relationship between the GDP and tourism income of Gaochun district, but it needs further analysis to prove whether it is causality. The Granger causality test method is used in this paper. Granger causality test is used to describe the interpretation degree of two variables on another variable series. It can be judged by null hypothesis and the smaller the hypothesis test probability is, the Granger causality of the two series is stronger. There must be at least one-way Granger causality relationship between two time series if there is a co-integration relationship between them. After proving the existence of co-integration relationship between GDP and tourism income of Gaochun district, there must be Granger causality between them. The Granger causality of tourism development and economic growth examines the lead-lag relationship pilot on time. The bivariate regression model estimated is as follows:

$$
\begin{aligned}
& y_{t}=C_{1}+\sum_{i=1}^{q} \alpha_{i} y_{t-i}+\sum_{j=1}^{q} \beta_{j} x_{t-j}+u_{1 t} \\
& x_{t}=C_{2}+\sum_{i=1}^{q} \lambda_{i} x_{t-i}+\sum_{j=1}^{q} \delta_{j} x_{t-j}+u_{2 t}
\end{aligned}
$$

in the formulas, $\mathrm{c}$ represents for constant, $u_{t}$ represents for random error term, and is a white noise. LGDP and LTOUR in the paper respectively represent for $y_{t}$ and $x_{t}$. If the null hypothesis $H_{01}: \beta_{1}=\beta_{2}=\cdots=\beta_{i}=0$ is rejected by the test, LTOUR does Granger cause LGDP, 
Table 3. ADF test results.

\begin{tabular}{ccccccc}
\hline \multirow{2}{*}{ Variables } & Inspection & \multirow{2}{*}{ ADF } & \multicolumn{3}{c}{ Test Critical Values } & \multirow{2}{*}{ Results } \\
\cline { 4 - 6 } & Type $(\mathrm{C}, \mathrm{T}, \mathrm{K})$ & & $1 \%$ & $5 \%$ & $10 \%$ & Non-stationary \\
LGDP & $(1,0,2)$ & 0.087001 & -4.297073 & -3.212696 & -2.747676 & Non-stationary \\
LTOUR & $(1,0,2)$ & -0.730994 & -4.297073 & -3.212696 & -2.747676 & Stationary \\
DLGDP & $(0,0,1)$ & -3.942670 & -4.420595 & -3.259808 & -2.771129 & Stationary \\
DLTOUR & $(0,0,1)$ & -3.680715 & -4.420595 & -3.259808 & -2.771129 & \\
\hline
\end{tabular}

Note: the test results in this table are calculated by Eviews 6.0.

Table 4. Characteristic root tracing test results.

\begin{tabular}{ccccc}
\hline $\begin{array}{c}\text { Hypothesized } \\
\text { No. of CE }(\mathrm{s})\end{array}$ & Eigenvalue & Trace Statistic & $\begin{array}{c}0.05 \text { Critical } \\
\text { Value }\end{array}$ & Prob. $^{* *}$ \\
\hline None $^{*}$ & 0.766066 & 13.23494 & 12.32090 & 0.0351 \\
At most $1^{*}$ & 0.017675 & 0.160501 & 4.129906 & 0.7404 \\
\hline
\end{tabular}

Table 5. Maximum characteristic value test results.

\begin{tabular}{ccccl}
\hline $\begin{array}{c}\text { Hypothesized } \\
\text { No. of CE (s) }\end{array}$ & Eigenvalue & $\begin{array}{c}\text { Max-Eigen } \\
\text { Statistic }\end{array}$ & $\begin{array}{c}0.05 \text { Critical } \\
\text { Value }\end{array}$ & Prob. $^{* *}$ \\
\hline None $^{*}$ & 0.766066 & 13.07443 & 11.22480 & 0.0234 \\
At most $1{ }^{*}$ & 0.017675 & 0.160501 & 4.129906 & 0.7404 \\
\hline
\end{tabular}

namely LTOUR can explain and predict LGDP, and if null hypothesis $H_{02}: \delta_{1}=\delta_{2}=\cdots=\delta_{i}=0$ is rejected by the test, LGDP does Granger cause LTOUR, and namely LGDP can explain and predict LTOUR [10]. The two hypothesis tests are both on the basis of F statistic test, namely:

$$
F=\frac{\frac{R S S_{R}-R S S_{U}}{m}}{\frac{R S S_{U}}{n-k}}
$$

In the formula, $m$ represents for lag period, $\mathrm{n}$ for sample size and $k$ for the number of parameters to be estimated of unconstrained regression model. The test results of Granger causality by Eviews6.0 is as shown in Table 6.

According to the results of Table 6, there is no causality relationship between tourism and economic growth when lag phase 2 and 3 , and when lag phase 1 , economic growth plays a leading role to the development of tourism.

\subsection{Impulse Response Analysis}

Impulse response reflects the impact on the current value and future value that one standard deviation from a random disturbance on endogenous variable. Before carrying on impulse response analysis, VAR model must be stable, so it is necessary to not only take the selection of lag order number but also the stationary of the model into consideration, to make sure the analysis of impulse response is effective [11]. According to the AIC, SC and HQ criteria, the lag order number is selected as 2 , it can be seen that there is one characteristic root on the edge of the unit circle, so VAR model is not stable when lag phase 2 (it can seen in Figure 3). When lag phase 1, the characteristic root are all in the unit circle, so VAR model is stable (it can be seen in Figure 4).

Under the premise of the stability of VAR model, we can get the impulse response function figure of LGDP by giving one unit of impact to LGDP and LTOUR. The horizontal axis represents the lag period number of the impact effect (this article select 10 as the number), the vertical axis represents the change degree of LGDP, and the solid line reflects impulse response function and reflects the impulse response when LGDP gives a standard difference new shock to each variable with the increase of forecast periods. The dotted line represents the confidence belt of the plus or minus standard deviation of the impulse response figure. The result of impulse response is as shown in Figures 5 and 6.

\section{Conclusions and Advice}

1) Although the time series of the tourism revenues and economic development of Gaochun District is nonstationary, it is stationary after first difference. The result of Co-integration Test shows that there exists a long-time stable relationship between the tourism revenues and GDP of Gaochun, which means that once the tourism revenue increases by 1 percent, the economy of Gaochun increase by 0.51 percent. The reason is because of the good material base and tourism environment which is good for the development of tourism that provided by the development of economy.

2) It can be seen from the result of Granger Causality Tests that there is no causal relationship between tourism and economic development when lap phase 2 and lap 3. But economic growth plays a leading role to the tourism development when lap phase 1 and there is a one-way causal relationship between the two. The reason why there doesn't show the leading role of tourism to economic growth is maybe because that the tourism of Gaochun started relatively late and the leading role is not so obvious.

3) It can also be seen from the Impulse Response Function that there is a positive impact between tourism and economic development. There are several aspects of 
Table 6. Results of granger causality test.

\begin{tabular}{ccccc}
\hline $\begin{array}{c}\text { Lag } \\
\text { Phase }\end{array}$ & Granger Causality & F Value & P Value & Conclusion \\
\hline $1 \quad \begin{array}{c}\text { LTOUR does not } \\
\text { Granger Cause LGDP } \\
\text { LGDP does not Granger } \\
\text { Cause LTOUR } \\
\text { LTOUR does not } \\
\text { Granger Cause LGDP }\end{array}$ & 0.10368 & 0.7569 & Accept \\
$2 \quad \begin{array}{c}\text { LGP does not Granger } \\
\text { Cause LTOUR } \\
\text { LTOUR does not } \\
\text { Granger Cause LGDP }\end{array}$ & 4.86552 & 0.40113 & 0.0849 & Accept \\
& $\begin{array}{c}\text { LGDP does not Granger } \\
\text { Cause LTOUR }\end{array}$ & 3.87754 & 0.7875 & Accept \\
\hline
\end{tabular}

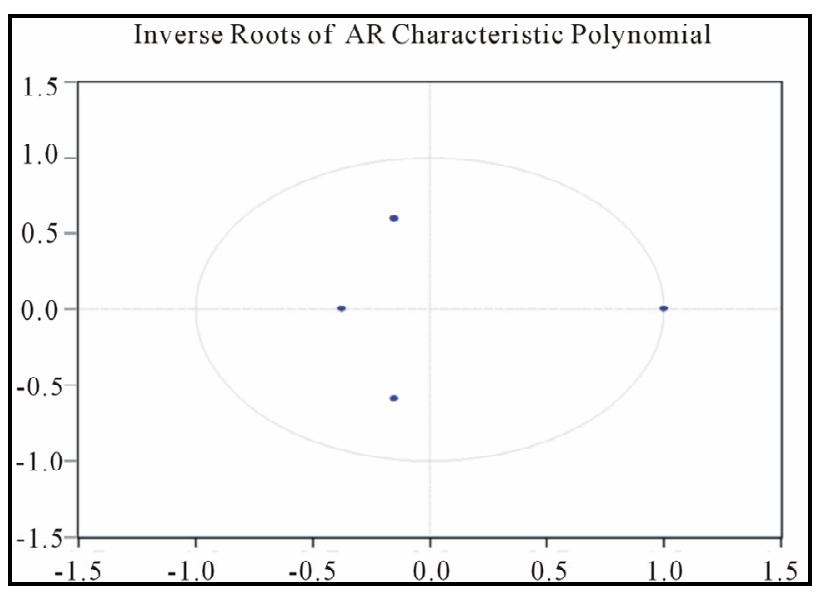

Figure 3. Stationary test result on lag phase 2.

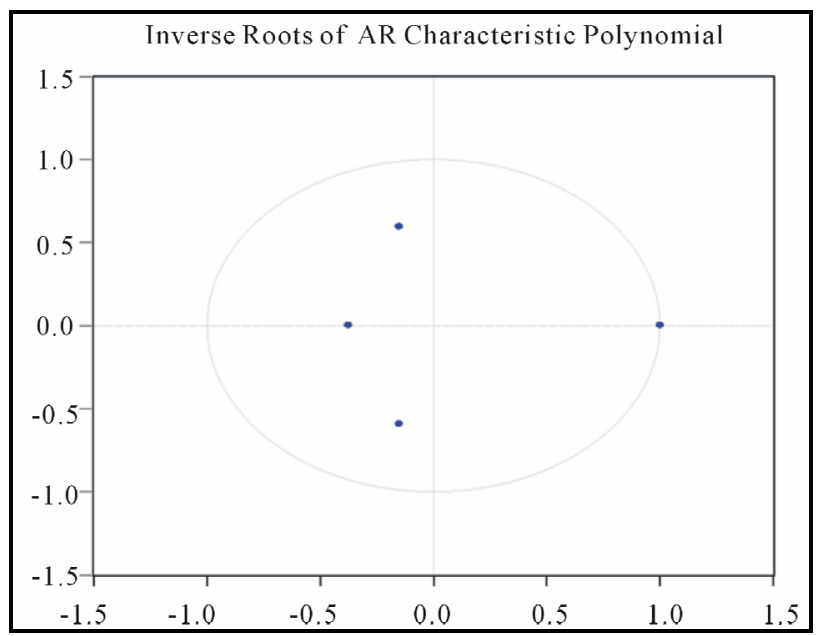

Figure 4. Stationary test result on lag phase 1.

the specific measures of developing tourism to drive regional economic growth. Firstly, improve the internal and external traffic conditions. Open the 6th metro light rail line- - Nanjing - Nanjing Lukou International Airport-Gaochun District", constantly improve the road between the towns and the tourist attractions. Secondly,

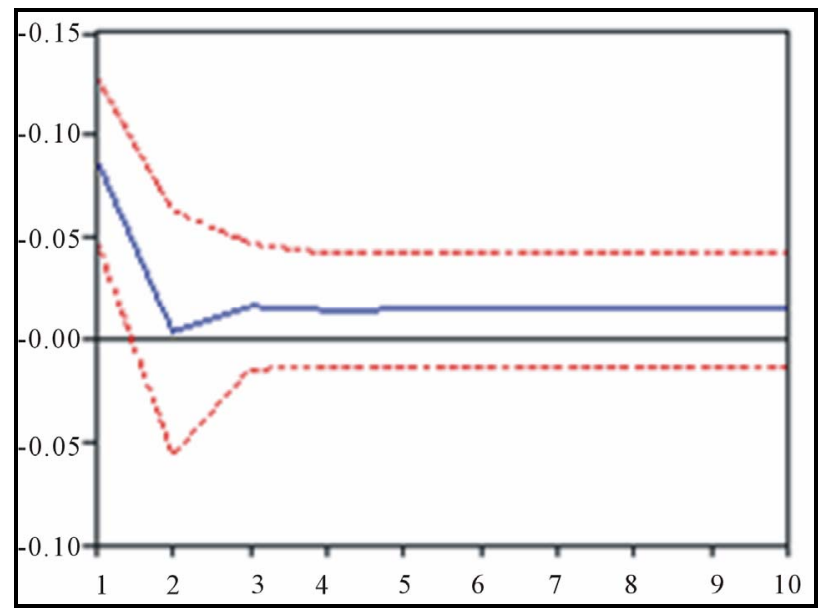

Figure 5. Impulse response figure of LGDP to LGDP.

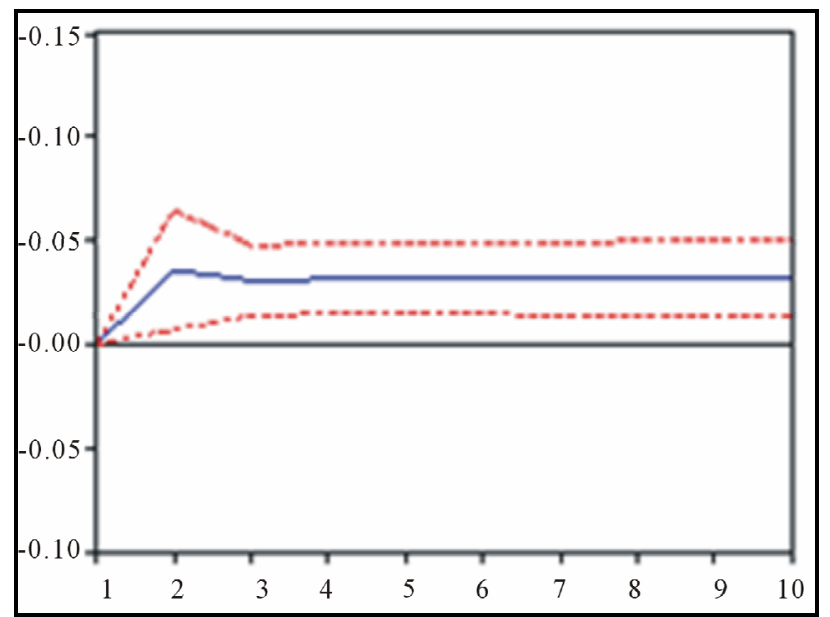

Figure 6. Impulse response figure of LGDP to LGDP.

conformity tourist resources and create tourist products, relying on the ecological tourism resources advantage based on the perfect combination of the mountain, water, agriculture and forest of Gaochun, mining its rich history and folk cultures, develop the leisure vacation travel, folk cultural tourism and rural eco-tourism. Thirdly, actively promote intergovernmental cooperation and communication, deepen the regional division of labor and cooperation, and implement the competition and cooperation strategy of tourism development.

\section{REFERENCES}

[1] N. Z. Lin and H. J. Tao, "Tourism Economics," Nankai University Press, Tianjing, 2000 (in Chinese).

[2] J. Balaguer and M. Cantavella-Jorda, "Tourism as a LongRun Economic Growth Factor: The Spanish Case," Applied Economics, Vol. 34, No. 7, 2002, pp. 877-884 doi:10.1080/00036840110058923

[3] P. K. Narayan, "Economic Impact of Tourism on Fiji's Economy: Empirical Evidence from the Computable Gen- 
eral Equilibrium Model," Tourism Economics, Vol. 10, No. 4, 2004, pp. 419-433.

doi: $10.5367 / 0000000042430971$

[4] N. Drisakis, "Tourism as a Long-Run Economic Growth Factor: An Empirical Investigation for Greece Using a Causality Analysis," Tourism Economics, Vol. 10, No. 3, 2004, pp. 305-316. doi:10.5367/0000000041895094

[5] H. J. Kim, M. H. Chen and S. C. Jang, "Tourism Expansion and Economic Development: The Case of Taiwan," Tourism Management, Vol. 27, No. 5, 2006, pp. 925-933. doi:10.1016/j.tourman.2005.05.011

[6] J. G. Brida, E. Carrera and W. A. Risso, "Tourism's Impact on Long-Run Mexican Economic Growth," Economics Bulletin, Vol. 3, No. 7, 2008, pp. 1-10

[7] G. Lin and X. B. Long, "Measure and Calculate on the Contribution of Guilin Tourism to National Economy," Journal of Guilin Tourism College, Vol. 3, 2000, pp. 7-12 (in Chinese).

[8] Z. Q. Li, "The Economic Analysis on the Output Contribution of Tourism-The Output Contribution and the Multiplier Effect of Tourism in Shanghai," Shanghai Economic Research, Vol. 12, 2001, pp. 66-68 (in Chinese).

[9] G. X. Wu, "The Correlation Analysis on Tourism Development and Economic Developmentin China," Journal of Shanghai College of Applied Technology (Natural Science Edition), Vol. 4, 2003, pp. 29-30 (in Chinese).

[10] Z. N. Li and W. Q. Pan, "Econometrics," 2nd Edition, Higher Education Press, Beijing, 2005 (in Chinese).

[11] G. M. Weng and C. Lu, "A Research on the Relationship between Tourism Development and Economic Development in China," Journal of Yanshan University, Vol. 1, 2012, pp. 56-57 (in Chinese). 